\title{
Effects of wind power spectrum analysis over resource assessment
}

Article

Accepted Version

Creative Commons: Attribution-Noncommercial-No Derivative Works 4.0

Lopez-Villalobos, C. A., Rodriguez-Hernandez, O., MartinezAlvarado, O. ORCID: https://orcid.org/0000-0002-5285-0379 and Hernandez-Yepes, J. G. (2021) Effects of wind power spectrum analysis over resource assessment. Renewable Energy, 167. pp. 761-773. ISSN 0960-1481 doi: https://doi.org/10.1016/j.renene.2020.11.147 Available at https://centaur.reading.ac.uk/94572/

It is advisable to refer to the publisher's version if you intend to cite from the work. See Guidance on citing.

To link to this article DOI: http://dx.doi.org/10.1016/j.renene.2020.11.147

Publisher: Elsevier

All outputs in CentAUR are protected by Intellectual Property Rights law, including copyright law. Copyright and IPR is retained by the creators or other copyright holders. Terms and conditions for use of this material are defined in the End User Agreement.

\section{www.reading.ac.uk/centaur}

\section{CentAUR}


Central Archive at the University of Reading

Reading's research outputs online 


\section{Highlights}

\section{Effects of wind power spectrum analysis over resource assessment}

C. A. Lopez-Villalobos, O. Rodriguez-Hernandez, O. Martínez-Alvarado, J. G. Hernandez-Yepes

- The annual power spectrum analysis shows a spectral gap region similar in amplitude to the microscale region.

- In the seasonal power spectrum analysis, we found a persistent spectral gap and the semi-diurnal peaks.

- Wind resource assessment using 6-hour or 1-minute mean times does not represent significant differences in power estimation.

- Wind resource assessment using reanalysis or WRF simulations can reproduce wind power production 


\title{
Effects of wind power spectrum analysis over resource assessment
}

\author{
C. A. Lopez-Villalobos ${ }^{\mathrm{a}, 1, *}$, O. Rodriguez-Hernandez $z^{\mathrm{a}, 2}, \mathrm{O}$. \\ Martínez-Alvarado $^{\mathrm{b}, 3}$, J. G. Hernandez-Yepes ${ }^{\mathrm{c}, 4}$ \\ ${ }^{a}$ Instituto de Energías Renovables, Universidad Nacional Autónoma de México, Priv. \\ Xochicalco s/n, Col. Centro, Temixco, Morelos CP 62580, México \\ ${ }^{b}$ National Centre for Atmospheric Science, Department of Meteorology, University of \\ Reading. Earley Gate, Reading, RG6 6BB, United Kingdom \\ ${ }^{c}$ Posgrado en Ingeniería, Universidad Nacional Autonoma de Mexico, Priv. Xochicalco \\ s/n, Col. Centro, Temixco, Morelos CP 62580, México
}

\begin{abstract}
Based on the Van der Hoven's seminal work, wind power industry has adopted the 10 minutes mean time as the proper sampling to estimate resource assessment. However, research within the literature questions the generalization of the 10 minutes as a standard measure of minima dispersion due to the particular geographic characteristics where the measurements took place. In this work is analyzed the power spectrum of a high-frequency wind speed time series and its influence over the resource assessment in the region of La Ventosa, Oaxaca, Mexico. Power spectrum analysis from a monthly, seasonal, and annual time series results show a defined synoptic-scale, diurnal, and semi-diurnal variations, which changes in amplitude throughout the year. To study the influence of power spectrum in wind resource assessment were estimated and compared the capacity factors of a typical 2MW wind turbine against measured wind speed with $1,5,10,60$, and 360 minutes mean times, we found that a maximum difference of $1.4 \%$. Resource assessment was also estimated using reanalysis data and WRF results, finding similar to
\end{abstract}

\footnotetext{
${ }^{*}$ Corresponding Author

Email address: calovi@ier.unam.mx (C. A. Lopez-Villalobos)

${ }^{1}$ ORCID: 0000-0002-7205-3764

${ }^{2}$ ORCID: 0000-0002-6567-4669

${ }^{3}$ ORCID:0000-0002-5285-0379

${ }^{4}$ ORCID:0000-0002-9325-2033
} 
high-resolution estimations, highlighting bias-corrected WRF performance, offering reliable results to model power performance after a statistical correction.

Keywords: Wind Resource Assessment, Wind Power Spectrum, WRF, MERRA-2, ERA5

\section{Introduction}

Wind power has become a crucial source of electricity generation in energy systems, and it will have an essential role in the future of global clean energy supply [1]. Mexico is the second-largest wind power producer in Latin 5 America with a total installed capacity of 6,215 MW at the end of 2019. The state of Oaxaca, in the south of the country, concentrates $44 \%$ of the total installed capacity of the country [2. Given the large installed capacity in the region, understanding the region's wind characteristics has important socioeconomic implications. Within Oaxaca, the region of La Ventosa has been

the subject of several studies to determine the region's wind characteristics [3, 4, 5].

The wind in the region exhibits a bimodal annual distribution which makes the typical Weibull fit an unreliable representation [4. Furthermore, the reliability of the Normal Turbulence Model (NTM), a fatigue load design parameter, of the IEC61400 standard [6, 7] has been shown to be unsuitable for the location [5].

Even though these are examples of the efforts to broaden wind energy knowledge in Mexico, there is no work related to wind speed power spectrum analysis, and specifically in La Ventosa, Oaxaca. The importance of the spectral gap relies in the fact that a mean time within this region is expected to have smaller variability than other regions, which could be assumed as a steady statistical sample. We can expect that any random sample averaged during such periods (for example, $3 \mathrm{~h}$ at $20 \mathrm{~min}$ ) will have a relatively narrow probability density function when compared to a set of similarly sampled random values using, for example, average speeds of one minute. Significant differences in wind resource assessment due to the selection of different mean times has been documented in the literature by Rodriguez-Hernandez et al. [8] and Tabrizi et al. [9]. They suggest that urban environments may have an influence in turbulence intensity and energy present in gusts. These effects may be studied analyzing both the wind power spectrum of the time series, 
for specific mean times, and the behavior of the dispersion.

Power spectrum applications on wind power are based on Van der Hoven's seminal work [10], whose main result consisted of characterizing the horizontal wind power spectrum. Van der Hoven analyzed the wind spectrum in a try as it constitutes the basis to set 10 min averages as the main input to characterize important parameters such as turbulence intensity, to develop reliable wind resource assessment, including turbulence intensity analysis. Van der Hoven wind spectrum used wind speed data obtained at three difLaboratory located in Upton, New York, USA. The author reported a set of average wind speed time series from 5-day to 2-sec. However, the data were not available at one height level. Van der Hoven used wind measurements recorded during the passage of hurricane Connie to describe and to clearly persion. Hurricane Connie came ashore near Cherry Point, North Carolina on 12 August 1955 (summer season) as a category 2 hurricane. On crossing the coastline, Connie weakened to tropical storm strength but remained an intense storm as it continued generally northward to near the latitude of tional Laboratory, the mean wind speed was $13 \mathrm{~m} / \mathrm{s}$, with a peak mean wind speed of $20 \mathrm{~m} / \mathrm{s}$ on 13 August 1955. Van der Hoven showed that assuming wind speed as a stationary random process, i.e., a random process whose statistical properties do not change with time, the wind spectrum presents Between them, around a period of $10 \mathrm{~min}$ lies a spectral gap, in which the time series exhibits minimum dispersion. However, Van der Hoven's analysis consisted of piecing together individual spectra over small frequency bands to infer a general behavior [12, 13, 14]. The wind speed data in Van der results interpretation difficult.

Wind spectrum results are relevant for wind speed forecasting [15] and for time series reconstruction [16]. This expected power spectrum behavior can be helpful due to the intermittency of the wind resource, which is still a challenge to ensure the quality of energy production and for the operation and maintenance of wind turbines.

There are some power spectrum analysis reports oriented to determine the frequency characteristics found by Van der Hoven. For instance, Kaya 


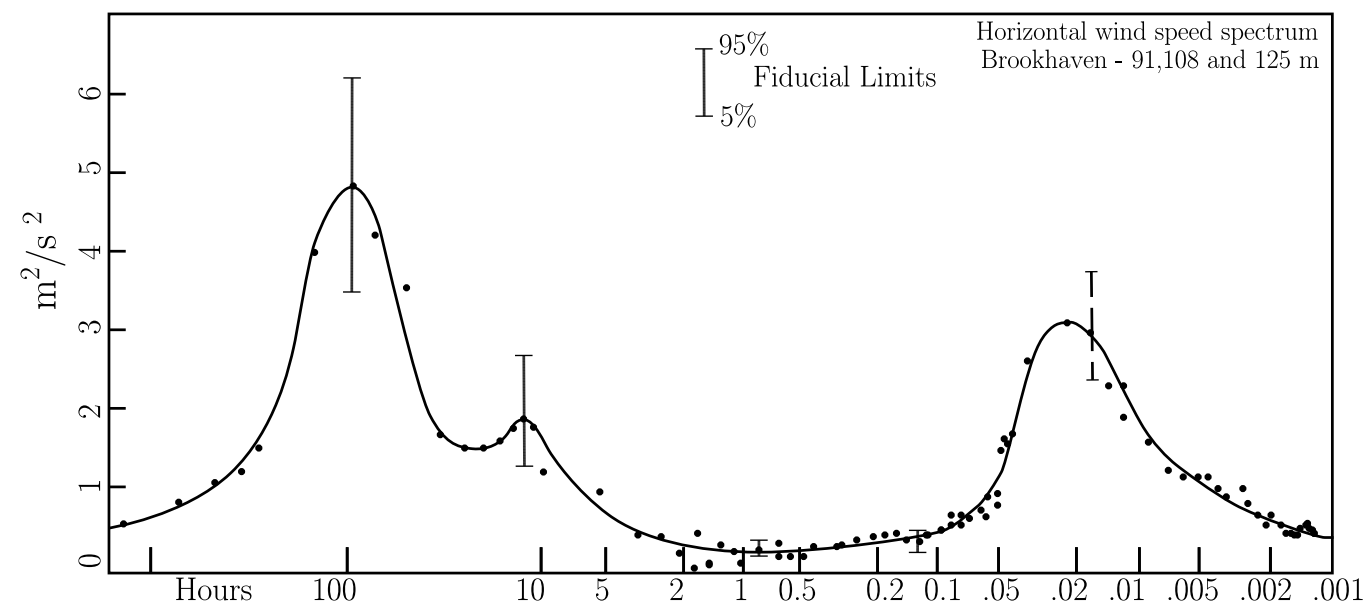

Figure 1: Schematic energy spectrum of near-ground wind speed of Van der Hoven (1957) 8.

et al. [16] report the power spectrum of surface wind speed (1 minuteaveraged) to evaluate contributions of disturbances at various scales on the total spectrum, finding a similar structure to the classic Van der Hoven spectrum. Furthermore, using an adaptive spectral analysis method called the Hilbert-Huang transform, Vincent et al. [17] showed that the spectral gap depends on the atmosphere's stability. The implementation of mesoscale and global atmospheric modeling on wind power research has become a recurrent alternative to study wind conditions for longer periods of analysis [18. A mesoscale model application for offshore wind resource assessment may be found in Chang et al. [19]. They combined multiple ocean satellite wind speed data and the Weather Research and Forecasting (WRF) simulations to acquire accurate reconstructed offshore wind speeds. Carvalho et al. 20] conducted different WRF simulations using six reanalysis as initial and boundary conditions. The results were compared to measured wind data collected at thirteen wind measuring stations located in Portugal in areas of high wind energy potential. The reanalyses used included ERA-Interim [21], NASA-MERRA [22] and NCEP-CFSR [23]. They found that ERA-Interim was the reanalysis that produced the best estimates of the local wind regimes and potential wind energy production. However, its time resolution is 6 hour, whereas the recommended time resolution in the wind energy sector to reliably represent the wind conditions of a site is $10 \mathrm{~min}$.

In this contribution, we perform a power spectrum analysis for the region 
of La Ventosa, Oaxaca, using high-frequency measurements. We focus on whether a spectral gap region is present in the measured data set. Furthermore, we explore the influence of the seasonal cycle on the power spectrum. Then, we estimate the impact of the power spectrum results on wind turbine influence of time resolution on the wind speed time series. Finally, capacity factor estimations were made with the reanalyses ERA5 [24] and MERRA2 [22] and the WRF model. These estimations were then compared with high-frequency estimations.

100

The structure of the present contribution is as follows. In section 2, we present the description of the measuring site, the characteristics of the meteorological equipment, and the measured data. In section 2, we also outline the theory and methods used to calculate the power density spectrum, wind power production, and capacity factor. In section 3, we show the following results: power spectrum of horizontal wind speed at the site, the relationship between power production and spectral gap, and a comparison of WRF model and data reanalysis against observations. Finally, in section 4, we present the conclusions.

\section{Theory and methods}

This section shows the methods and theory implemented through the present contribution. First, we describe the geographic location of the region of analysis and the characteristic of the high frequency measured data. Then, we present the numerical mesoscale models selected, the methodology to calculate the power spectrum of the horizontal wind speed and the procedure to estimate annual wind turbine power production as well as the capacity factor.

\subsection{Measurement site and data processing}

The measurement site is located in La Ventosa, Oaxaca $\left(16^{\circ} 32^{\prime} 40.8^{\prime \prime}\right.$ North, $94^{\circ} 57^{\prime} 09.0^{\prime \prime}$ West) in the Tehuantepec Isthmus region (See Figure

$2 \mathrm{~b}$ for the location of the geographical features referred to in the text). This region is of special interest given that it concentrates the greatest wind potential in Oaxaca due to the strong mountain gap wind traveling through the Chivela Pass into the eastern Pacific coast in southern Mexico, most commonly between October and February [25]. The synoptic condition is associated with advancing cold fronts over the Gulf of Mexico blocked by the 
mountain chain known as the Sierra Madre, which results in the development of a north-south pressure gradient through the Isthmus [26].

Two anemometers WindMaster 3D were installed on an anemometrical mast at 17.5 and 40 meters above ground level. The anemometers have a frequency output of $20 \mathrm{~Hz}$ for temperature, pressure and the three wind

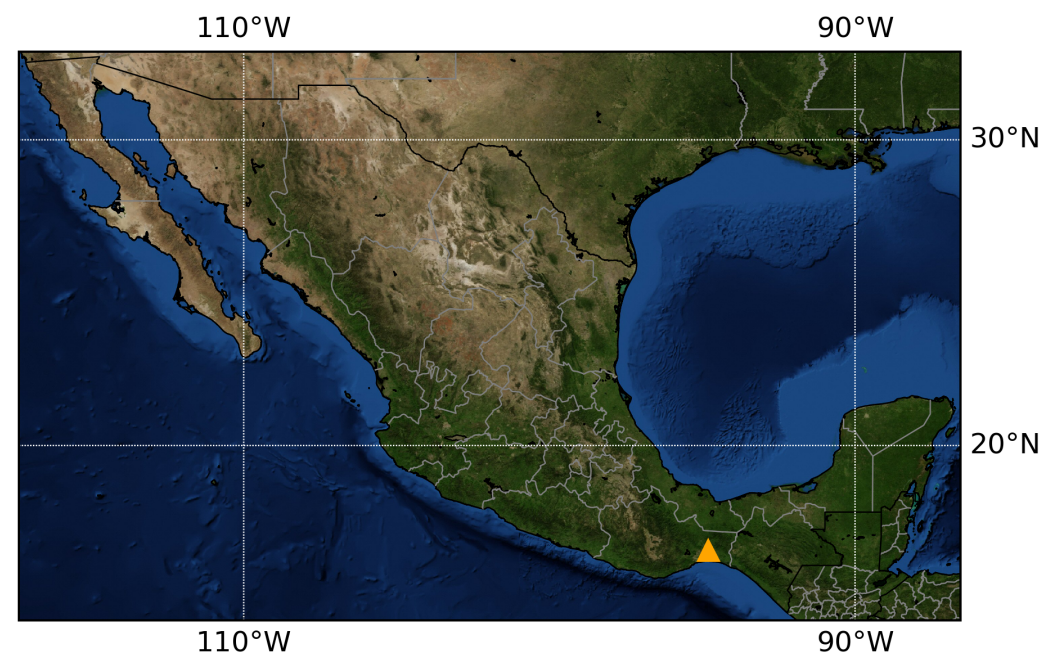

(a) Map of the Mexican republic illustrating the location of the state of Oaxaca.

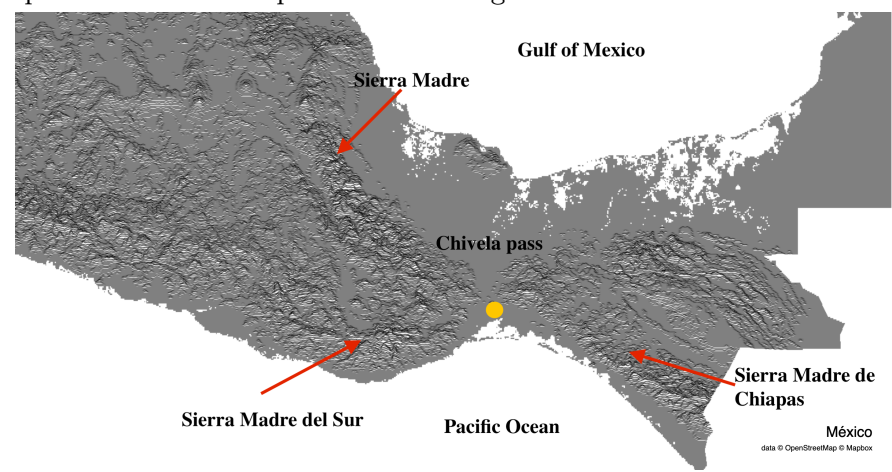

(b) Location of the site measurement, La Ventosa in the state of Oaxaca

Figure 2: Geo-localization of the site measurement implemented at La Ventosa, the Isthmus of Tehuantepec, Oaxaca, Mexico ( $16^{\circ} 32^{\prime} 40.8^{\prime \prime}$ North, $94^{\circ} 57^{\prime} 09.0^{\prime \prime}$ West) 
components. Wind speed is measured in a range between 0 and $50 \mathrm{~m} / \mathrm{s}$ is measured with a resolution of $0.01 \mathrm{~m} / \mathrm{s}$; wind direction is measured in a range from 0 to $359^{\circ}$ with a resolution of $0.01^{\circ}$. In both cases, the data is measured using digital and analogical outputs. The data was saved at a

135 frequency of $1 \mathrm{~Hz}$ to characterize the wind turbulent kinetic energy within the period of August 2017 to July 2018. In the present study, we only use the 40-m anemometer dataset for the power spectrum study, wind resource assessment, and the comparison with meteorological models. However the power spectrum analysis of the 17.5-m anemometer yielded similar results.

\subsection{Numerical meteorological models}

We selected the wind speed time series at 1 hour mean time of the meteorological model, WRF, and two reanalyses, namely MERRA-2 [22] and ERA5 [24]. Reanalysis is the process whereby a fixed version of a numerical weather prediction model, equipped with a data assimilation system, is used to reprocess available meteorological observations and provide a consistent set of gridded meteorological fields, typically spanning an extended segment of the historical data record [27]. The horizontal grid spacing of MERRA-2 is $0.5^{\circ}$ latitude and $0.625^{\circ}$ longitude, and ERA5 is $0.5625^{\circ}$.

The WRF model is a numerical weather prediction model which supports both atmospheric research and weather prediction. The simulation is centered on the location of the measurement site. We employ 4 one-way nested domains, shown in Figure 3. The horizontal spacing from the outermost (Domain 1: D01) to the innermost (Domain 4: D04) domains are $75 \mathrm{~km}, 15$, $3,1 \mathrm{~km}$, respectively, with the NCEP-FNL analysis [28] as input for initial and boundary conditions, and the set of parameterizations listed in table 1. The corresponding numbers of grid points are $56 \times 56,81 \times 81,96 \times 96$, and $178 \times 163$. The innermost domain is employed to extract a time series to compare with the measured data.

To estimate wind speed at the particular location of the anemometric tower, the horizontal wind components at $10 \mathrm{~m}$ and at $50 \mathrm{~m}$ (MERRA-2) and $100 \mathrm{~m}$ (ERA5 and WRF) are first bilinearly interpolated to the position of the tower. Using the wind components at the altitudes above ground level indicated above, wind speed is computed and then vertically interpolated to the position of the instrument at $40 \mathrm{~m}$, assuming a logarithmic profile. The application of this methodology results in a wind speed time series corresponding to the observed period between August 2017 and July 2018. The 
Table 1: WRF parameterizations used in the present work

\begin{tabular}{cc}
\hline Physics options & Scheme used \\
\hline Radiation-shortwave & Dudhia (1989) \\
Radiation-longwave & RRTM \\
Microphysics & Lin et al. scheme (1983, JCAM) \\
Cumulus & Kain-Fritsch Kain (2004, JAM) \\
Boundary layer & YSU Hong, Noh and Dudhia (2006, MWR) \\
Surface layer & (MM5 similarity) \\
Land surface & Noah Land Surface Model \\
\hline
\end{tabular}

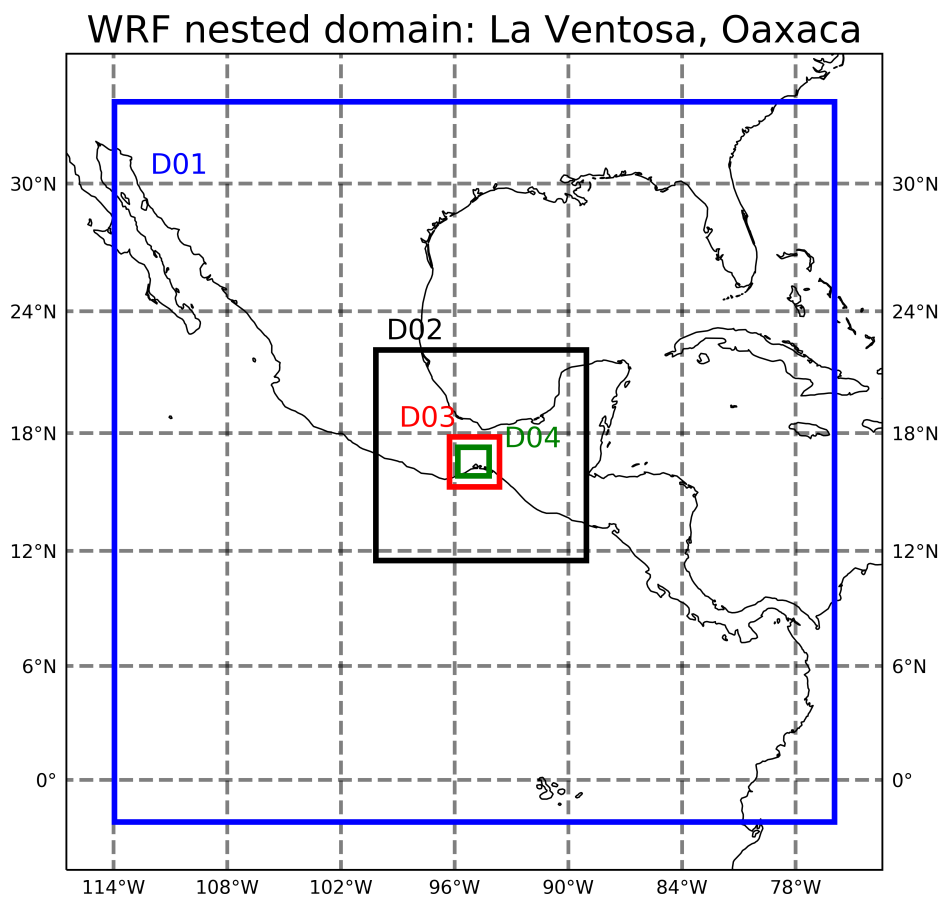

Figure 3: Domains used in the WRF model centered in La Ventosa, Oaxaca, Mexico. Domain dimensions: $4200 \mathrm{~km} \times 4200 \mathrm{~km}$ (domain D01), $1215 \mathrm{~km} \times 1215 \mathrm{~km}$ (domain D02), $288 \mathrm{~km} \times 288 \mathrm{~km}$ (domain D03) and $178 \mathrm{~km} \times 163 \mathrm{~km}$ (domain D04) 
time series is bias-corrected by means of the quantile mapping biased correction method [29] to ensure a realistic daily and inter-annual variability of the three different models when compared with the measured data.

\subsection{Power spectrum estimation method}

The discrete Fourier transform $F_{u}(n)$ is computed according to

$$
F_{u}(n)=\sum_{k=0}^{N-1}\left[\frac{u(k)}{N}\right] \mathrm{e}^{-i 2 \pi n k / N}
$$

where $n$ is the frequency and $u(k)$ is the original time series with $N$ data points. After the calculation of the Fourier transform, the spectrum is smoothed to reduced the overlap of the spectral estimations of any frequency and noise [30]. Following [30], a multitaper spectral methodology is implemented in the present work. The difficulties and comparisons of different methods for spectral analysis is beyond the scope of this paper, but more information can be found in [31, 32, 33]. Based on the above research work, here, we employed an adaptive sine multitaper method made available by [34. This is a multitaper method which in principle is not different from other non-parametric direct spectral estimates. This method consists in reducing the effects of the spectral leakage and to apply a multitaper method to the time series, by multiplying $u(t)$ by a carefully selected multitaper function $\phi_{k}(t)$ before the Fourier transform calculations. This method result in a spectrum, which is a convolution of the periodogram, with $\left|\Phi_{k}(f)\right|^{2}$, where $\Phi_{k}(f)$ is the Fourier transform of $\phi_{k}$. In conclusion, this multitaper method works averaging multiple single-taper spectra that are calculated from a set of special orthogonal tapers to achieve maximum suppression of random variability. In traditional methods the same is accomplished by a frequency domain smoothing [35].

\subsection{Wind power production and capacity factor calculations}

In wind power projects, it is essential to determine the wind energy potential of a specific site. Regarding this analysis, it is recommended to have ten-minute wind speed time series and the wind turbine power curve of the technology to assess for determining the viability of a site. In the present contribution, we propose the wind turbine power curve of Vestas V90-2MW, which is a three-bladed upwind horizontal-axis. Vestas V90 has a rotor diameter of 90 meters, with rotor blades of 44 meters long, and a hub-height 
of 80 meters above surface level. The wind turbine starts to produce electric 200 power at a wind speed of $3 \mathrm{~m} / \mathrm{s}$, reaching its nominal power output of $2 \mathrm{MW}$ at $13.5 \mathrm{~m} / \mathrm{s}$, and the survival wind speed is $25 \mathrm{~m} / \mathrm{s}$, cutting off the power production (pitch power control).

The energy production of a wind turbine per unit of area, $E_{W} / A$, for a given time series with $N$ data points with a time interval, $\Delta t$, is defined as follows [36]:

$$
\frac{E_{W}}{A}=\sum_{i=0}^{N-1} P_{W}\left(V_{i}\right) \Delta t,
$$

where $P_{W}$ is the wind turbine power production as a function of the wind speed, $V_{i} \geq 0$.

The capacity factor is defined as a dimensionless ratio of the real power output and the nominal power output of a wind turbine in a giving period (usually annual). It is computed as [37]

$$
C F=\frac{E_{W}}{P_{R} \times y_{h}},
$$

where $P_{R}$ is the nominal power output of a wind turbine and $y_{h}$ is the number of hours in the period of time to evaluate. This is a valuable measure of the annual wind power production compared to its operation at full potential or rated capacity in a period of interest.

\section{Results}

In the present section, we introduce a seasonal power spectrum analysis of the 1-s horizontal wind speed time series. As a first approach, we perform monthly analysis of the wind speed measured data and a comparison against the 39 years of the bias-corrected reanalysis data to determine possible atypical behavior in the measured data. Furthermore, we implement an annual and seasonal power spectrum analysis, and we also conduct a seasonal analysis of the wind speed measured data. Then, we proceed to find

225 a relation between power production and the microscale-spectral gap region. Finally, we perform a comparison of the WRF model results and reanalysis data against observations. 


\subsection{Comparison of the measured and reanalysis data}

In Figure 4 the lowest dispersion corresponds to August (Summer) and the greatest to March (Spring). Considerable high dispersion occurs in October, November, December, January, and February, which correspond to the high wind speed seasons, namely fall and winter. August has both the lowest dispersion and lowest monthly maximum wind speed values. The monthly maximum wind speed values are around $30 \mathrm{~m} \mathrm{~s}^{-1}$ from October to April with a clear exception in January, which exhibits a peak around $40 \mathrm{~m} \mathrm{~s}^{-1}$. Within this period the median value starts increasing reaching a maximum in January.

To place the wind speed during the observation period in the context of the local climatology, we compare this against long-term bias-corrected time series derived from MERRA-2 and ERA5, for the 38-year period between 1980 and 2018. The bias correction was trained using the measured data from August 2017 to July 2018. A comparison between the observations and the bias-corrected reanalyses data for the same period is shown in figure 5. The correlation coefficient between observations and ERA5 is $r=0.81$

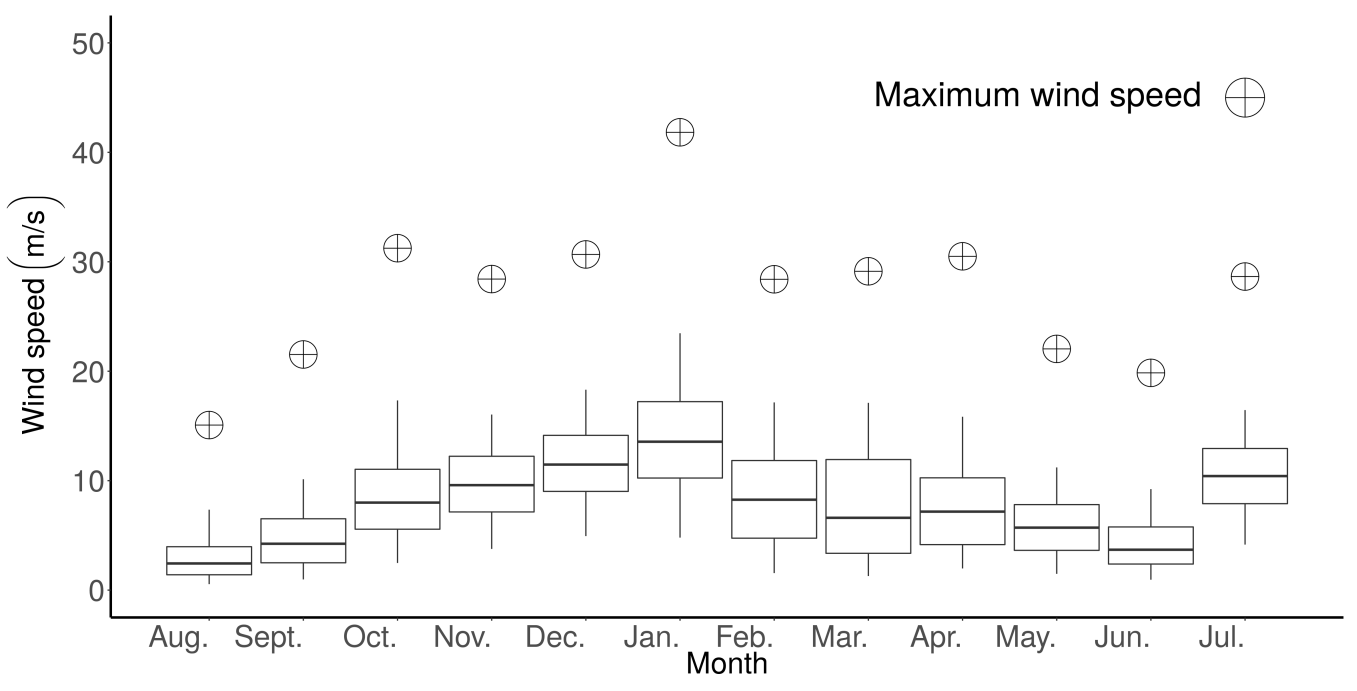

Figure 4: Box plot of the monthly wind speed variation from August 2017 to July 2018 at La Ventosa, Oaxaca, Mexico (40 m high). The symbol $\bigoplus$ represents the monthly maximum value of the data. The interquartile region is used to represent the dispersion of the monthly data. Maximum values are for the months of October to February, with wind speeds from 15 to $42 \mathrm{~m} \mathrm{~s}^{-1}$. During January appears the maximum wind speed of the year. 
245 (figure 5a), while the corresponding coefficient for MERRA-2 is $r=0.76$ (figure 5b). The Q-Q plot constructed using the raw reanalysis data is also shown. As the wind speed increases the Q-Q difference also increases under the identity line, which can be interpreted as an underestimation of the wind speed, which directly influences the quality of adjustment with the data.

Figures $6 \mathrm{a}$ and $6 \mathrm{~b}$ show the boxplot of the 39 years of bias-corrected ERA5 and MERRA-2, respectively. Both reanalyses showed similar behavior, exhibiting a higher median and dispersion values in the winter season, with a maximum in January, and reaching the lower wind speed values in the summer season, with a minimum in June, and starting to increase towards winter again, December. In the figures, the red triangles represent the median value of the 40-m measured wind speed, and the blue triangle represents the median values in ERA5 and MERRA-2. While the reanalyses track the observations throughout the year, both reanalyses tend to overestimate the monthly median values for the observation period. One notable exception is July, in which the observations lie above both reanalyses' interquartile

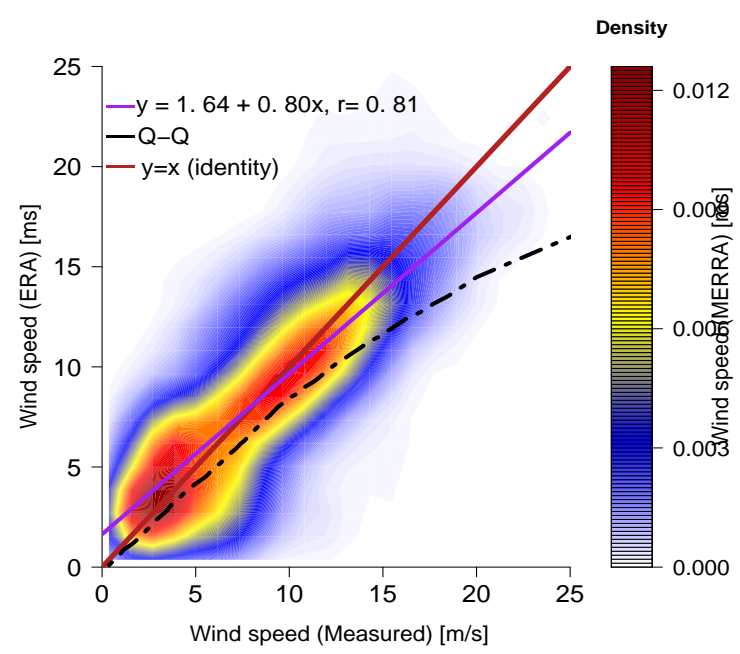

(a) ERA 5

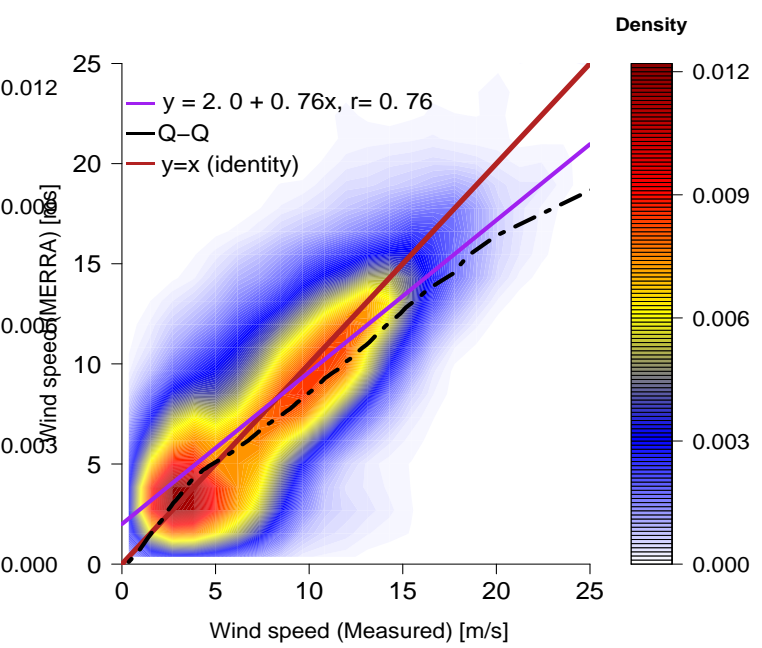

(b) MERRA-2

Figure 5: Comparison between measured data and reanalyses models. The linear regression for bias (purple straight line) correction has a correlation coefficient $r$ above 0.75 for both reanalyses data, which can be considered as a good approximation. The color mapping corresponds to the probabilistic density of the wind speed which shows a bi-modal behavior. It is also presented the identity line (dark-red line). 
ranges. The corresponding reanalysis-derived medians do lie between the second and third quartiles still highlighting strong wind speeds during that month.

\subsection{Power spectrum estimations of the horizontal wind speed}

Figure 7 shows the power spectrum of the data set for the whole observing period with the microscale region and the energy gap clearly defined, and the semidiurnal and diurnal effects, 12 -h and 24 -h periods, respectively. The horizontal axis represent the period on a logarithmic scale and the vertical axis represent the product of the frequency and energy spectrum, $f S(f)$. There are two other clearly defined peaks at 29 and 5 days. The presence of peaks at 5 days might be due to the increase of cyclonic activity [38]. We can relate this to the strong north winds in La Ventosa, which are a consequence of a low-rise corridor created by the Sierra de Chiapas and the Sierra Norte de Oaxaca, driven by tropical-mid-latitude interactions. The spectral gap is between 12 minutes and 2 hours and appear to be centered at a period of 0.5 $\mathrm{h}$ with an amplitude around $0.3 \mathrm{~m}^{2} \mathrm{~s}^{-2}$.

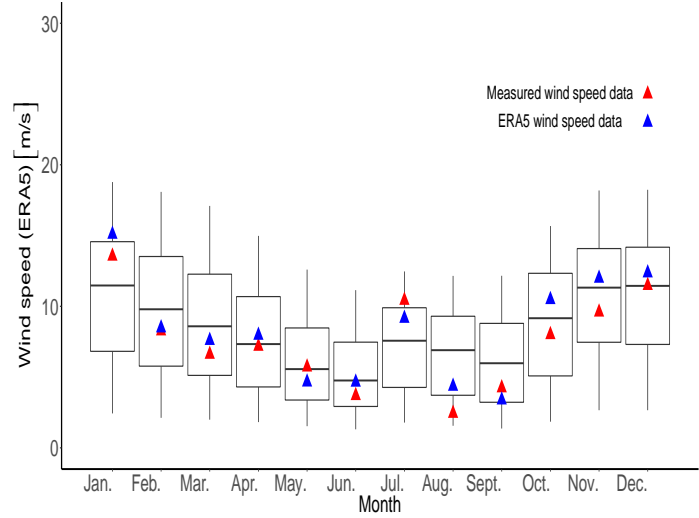

(a) ERA5 wind speed time series data

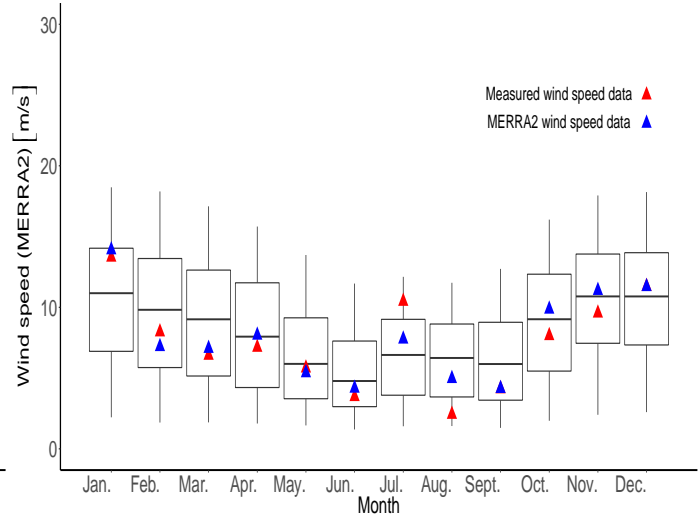

(b) MERRA-2 wind speed time series data

Figure 6: A comparison of the monthly mean wind speed from ERA5 and MERRA-2 bias-corrected at La Ventosa, Oaxaca, Mexico (40 m high) from 1980 to 2018 (box plots), and real wind speed data from August of 2017 to July of 2018 (red triangle). The blue triangle is the time series for the same period but from the reanalysis models. 
From the power spectrum results, we found similar low dispersion between the spectral gap and microscale region. This behavior is a persistent wind condition with similar dispersion no matter the mean time used. To analyze the power density spectrum of the wind resources of a specific site, the recommended 10-minute average period from the Van der Hoven spectrum is usually used. However, in the present work, a completely different power spectrum is found for La Ventosa: it has a microscale region not so different in amplitude compared to the minimum energy region. The power spectrum results suggest that a mean time within this region is expected to have smaller variability than other regions, which could be assumed as a steady statistical sample. There are some works in the mid-latitudes where it was found a spectral gap and semi-diurnal, diurnal, and synoptic peaks [39, 40, 41]. However, at high-latitudes a lack of the spectral gap has also been reported [42].

Now, to know if the spectral gap depends on the annual cycle, we conduct a power spectrum analysis by season (figure 8). However, due to the characteristic of the available data time series, we define the seasons as follows: 1)

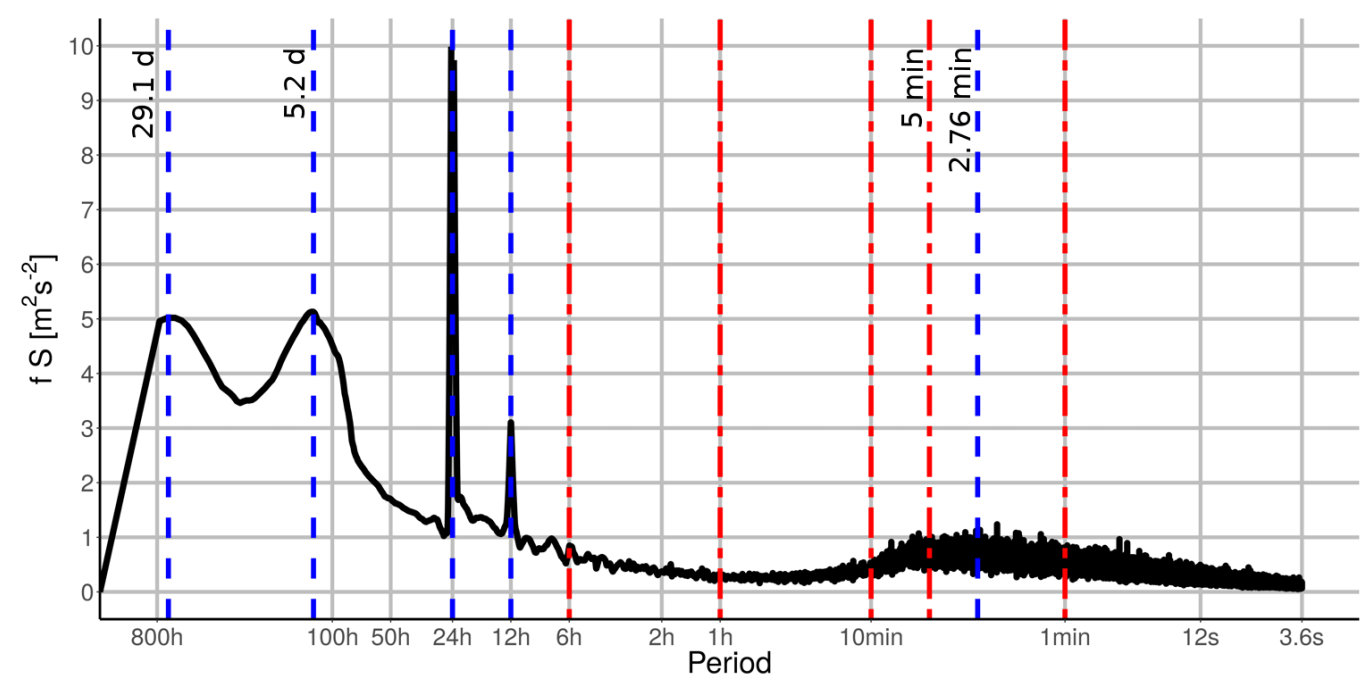

Figure 7: Power spectrum of the horizontal wind speed at La Ventosa, Oaxaca, Mexico for $40 \mathrm{~m}$ high anemometer from August, 2017 to July, 2018. The microscale region and energy gap are clearly defined, as well as the diurnal effects at 12 hours and the peak corresponding to synoptic scale at 5.2 days and in a peak at 29.1 days. The red vertical lines correspond to the mean times $(1,5,10,60$, and 360 minutes) used in the analysis (see text). 


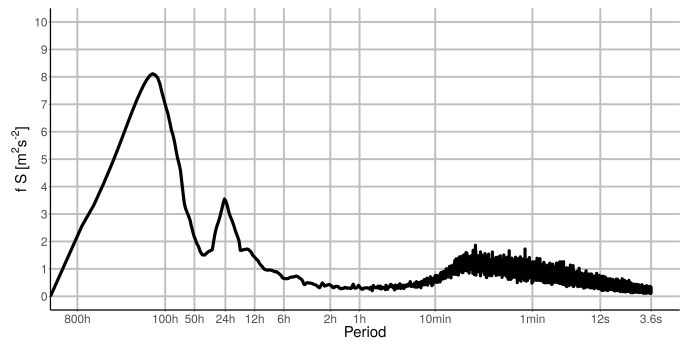

(a) Winter season

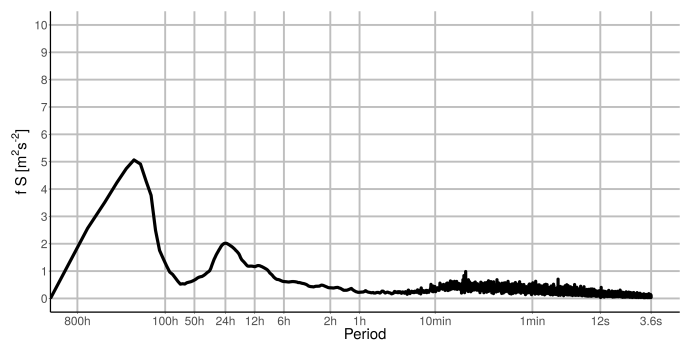

(c) Summer Season

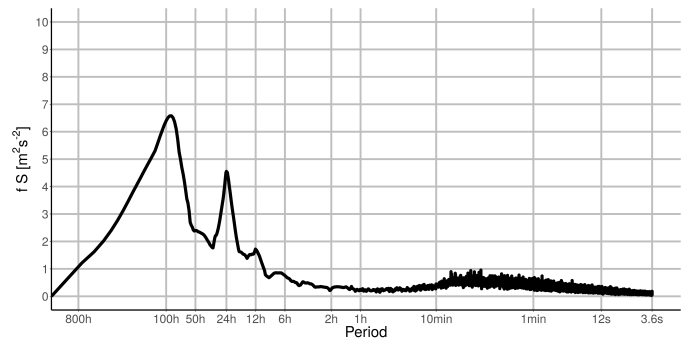

(b) Spring season

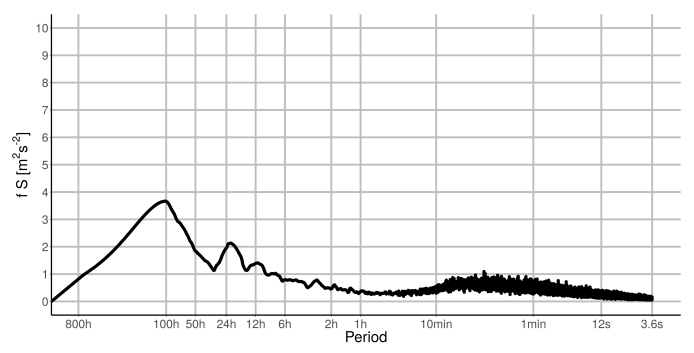

(d) Fall season

Figure 8: Seasonal behavior of the power spectrum of the horizontal wind speed from August of 2017 to July of 2018. We define the seasons as follows: Winter (December 2017, January 2018, and February 2018), Spring (March 2018, April 2018, and May 2018), Summer(June 2018, July 2018, and August 2017), and Fall (September 2017, October 2017, and November 2017)

winter (December 2017, January 2018, and February 2018), 2) Spring (March 2018, April 2018, and May 2018), 3) Summer(June 2018, July 2018, and August 2017), and 4) Fall (September 2017, October 2017, and November 2017). Figures $8 \mathrm{a}$ to $8 \mathrm{~d}$ show the winter, spring, summer, and fall seasons, respectively. In all season power-spectrum results three main regions are identified (from right to left): microscale, spectral gap, and macroscale. The latter includes diurnal and synoptic scales. The spectral gap is centered around the period of 0.5 hour and separates the microscale and macroscale regions.

Figure $8 \mathrm{a}$ shows the power spectrum of the winter season with the maximum peak around the $8 \mathrm{~m}^{2} \mathrm{~s}^{-2}$ near the 100 hours and has the highest microscale region of all seasons. It also presents a 24 -hour peak, but it does 
not have a clear 12-hour peak. Figure 8b shows the Spring power spectrum with a maximum peak around $6.5 \mathrm{~m}^{2} \mathrm{~s}^{-2}$ at a period of 100 hour. There is a peak around the 24-hour and smaller clear peak at 12-hour. Figure 8c shows the Summer power spectrum with a peak around $5 \mathrm{~m}^{2} \mathrm{~s}^{-2}$ at 200-hour. Summer presents a peak at 24 hours and there is no a clear peak around the 12 hours, however shows a relatively flat microscale behaviour. Figure 8d shows the Fall power spectrum with a peak at a period of $100 \mathrm{~h}$ around $3.5 \mathrm{~m}^{2} \mathrm{~s}^{-2}$. There is a smaller peak at 24 hour and it also has a no so clear peak around the 12 hours and also it shows a relatively flat microscale behaviour. For all seasons, the spectral gap region is between 2 and 0.2 hours and center at 0.5 hour with an amplitude between 0.2 to $0.4 \mathrm{~m}^{2} \mathrm{~s}^{-2}$. Summarizing, the amplitude of the 100-hour wave period of the power spectrum starts increasing in Fall, reaches its maximum in Winter, and continues to decrease in Spring and Summer.

Extreme wind speed in the region is the combination of complex large scale meteorological and local topographic conditions around Chivela Pass. Winds have strong seasonal signal, with maximum values during December to January, and minimum during May to June, and a relative maximum in July [43, 44, 45]. Strong wind speeds occurs mainly in winter months due to cold air damming in the wake of cold fronts that reach as far south as the Bay of Campeche. This highly turbulent phenomena is consistent with the power spectrum analysis presented.

Finally, from the seasonal power spectrum results, it is clear that there are marked differences in the amplitude of the diurnal and semi-diurnal behavior. Therefore, it is convenient to analyze the wind speed behavior through seasons, clustering by hours to reproduce a typical day. The objective is to identify seasonal wind speed patterns that can be related to the dispersions found in the seasonal wind spectrum. Figure 9 shows the daily wind speed density probability distribution clustered by season as follows: Winter (December 2017, January 2018, and February 2018), Spring (March 2018, April 2018, and May 2018), Summer(June 2018, July 2018, and August 2017), and Fall (September 2017, October 2017, and November 2017). The white diamonds are the mean, and the error bars are the mean \pm one standard deviation of the hourly values of the period. In all seasons, the mean wind speed shows the same tendency: after midnight, the mean is nearly constant, then after sunrise, there is an increase in the mean wind speed, and finally, after sundown, the mean wind speed tends to decrease. We observe almost constant error bars length, with an increase of wind speed dispersion around 
10 to 12 hours. In table 2 a summary of the mean and standard deviation of the hourly values by the season of the year is shown, which we can identify with the semi-diurnal and diurnal cycle of the seasons that we just described.

Figure 9a shows the Winter season density probability of wind speed. We

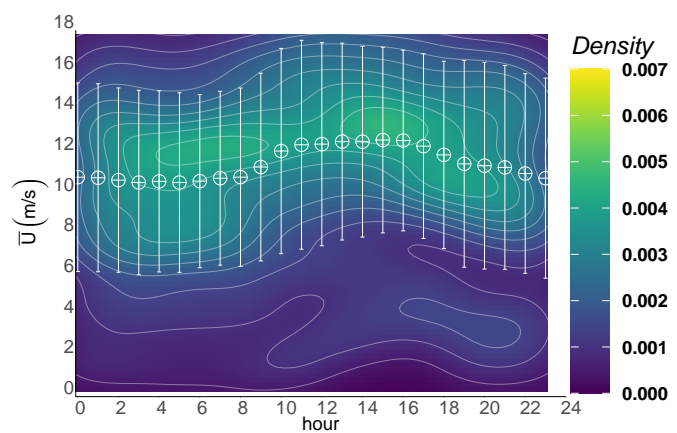

(a) Winter season

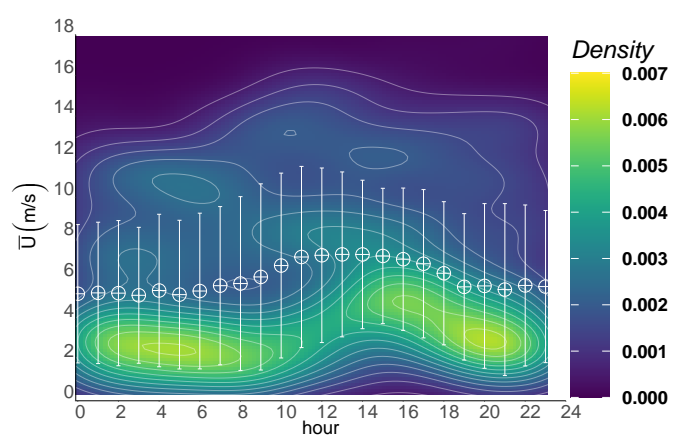

(c) Summer Season

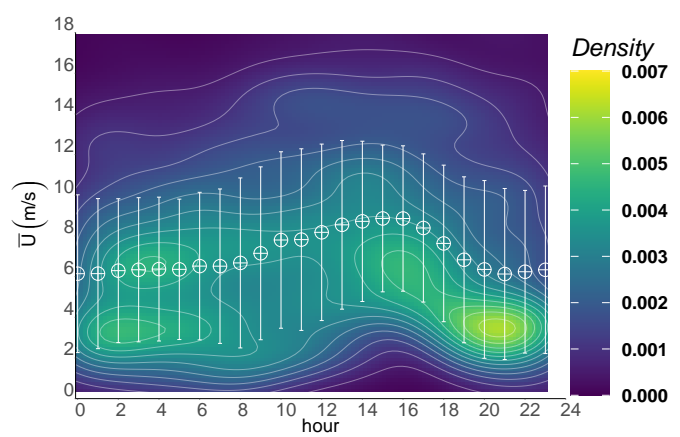

(b) Spring season

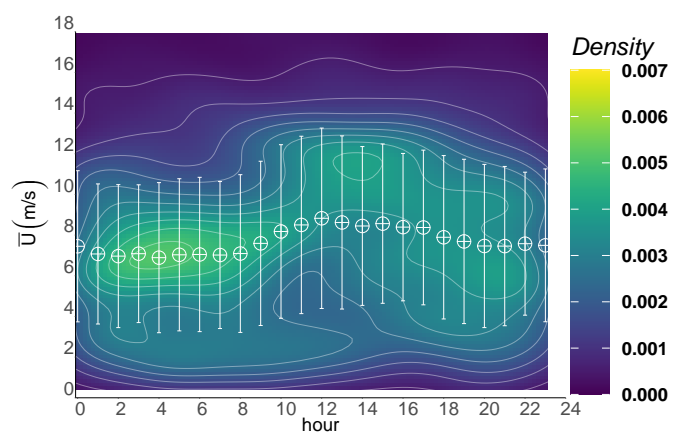

(d) Fall season

Figure 9: Seasonal behaviour of horizontal wind speed from August of 2017 to July of 2018. We grouped the seasons as Winter (December 2017, January 2018, and February 2018), Spring (March 2018, April 2018, and May 2018), Summer(June 2018, July 2018, July 2018, and August 2017), and Fall (September 2017, October 2017, and November 2017). The color mapping corresponds to the probabilistic density of the wind speed and the white diamonds are the mean wind speed 
observe a strong 24-hour behavior that masked the 12-hour. This might be the reason for the clear 24-hour peak in the power spectrum results, and the absence of the 12-hour peak. The fall (figure 9d) has a similar behavior top the winter. However, the major difference between these two seasons is the higher variance due to higher wind speed exhibited by the winter season. That could be the reason of the higher amplitude in the peak at 24-hour. Figure $9 \mathrm{~b}$ shows the Spring season density probability of wind speed. It is visible that the season has a 24-hour behavior, however, it also has a semi-diurnal component, where it has higher density probability values for 4 hours passing midnight and 5 hours passing 18:00, which it is also identified in table 2. Figure 9c shows the Summer season density probability of wind speed. It has a strong 24-hour behavior, but due to the narrow wind speed dispersion( in table 2 it exhibits the lowest standard deviation), i.e. higher density probability distribution concentrated between 2 and $6 \mathrm{~ms}^{-1}$. This translates into a lower 24-hour peak amplitude in the spectrum.

Table 2: Mean and standard deviation for each hour during a day grouped by the season of the year: Winter (December 2017, January 2018, and February 2018), Spring (March 2018, April 2018, and May 2018), Summer(June 2018, July 2018, July 2018, and August 2017), and Fall (September 2017, October 2017, and November 2017).

\begin{tabular}{|c|c|c|c|c|c|c|c|c|c|c|c|c|}
\hline & \multicolumn{12}{|c|}{ Hour during a day } \\
\hline & $\mathbf{0}$ & 2 & 4 & 6 & 8 & 10 & 12 & 14 & 16 & 18 & 20 & 22 \\
\hline & \multicolumn{12}{|c|}{ Winter season } \\
\hline Mean $(\mathrm{m} / \mathrm{s})$ & 10.7 & 10.6 & 10.5 & 10.5 & 10.7 & 12.0 & 12.4 & 12.5 & 12.5 & 11.8 & 11.3 & 10.9 \\
\hline \multirow{2}{*}{ Standard Deviation $(\mathrm{m} / \mathrm{s})$} & 4.6 & 4.5 & 4.5 & 4.2 & 4.3 & 5.0 & 5.9 & 4.6 & 4.4 & 4.6 & 5.0 & 4.9 \\
\hline & \multicolumn{12}{|c|}{ Spring season } \\
\hline $\operatorname{Mean}(\mathrm{m} / \mathrm{s})$ & 6.1 & 6.2 & 6.3 & 6.5 & 6.6 & 7.8 & 8.1 & 8.7 & 8.8 & 7.6 & 6.3 & 6.2 \\
\hline \multirow[t]{2}{*}{ Standard Deviation $(\mathrm{m} / \mathrm{s})$} & 3.8 & 3.5 & 3.5 & 3.6 & 4.1 & 4.3 & 4.3 & 3.9 & 3.5 & 3.8 & 4.3 & 3.9 \\
\hline & \multicolumn{12}{|c|}{ Summer season } \\
\hline $\operatorname{Mean}(\mathrm{m} / \mathrm{s})$ & 5.2 & 5.2 & 5.4 & 5.3 & 5.7 & 6.6 & 7.1 & 7.1 & 6.9 & 6.2 & 5.6 & 5.6 \\
\hline \multirow{2}{*}{ Standard Deviation $(\mathrm{m} / \mathrm{s})$} & 3.4 & 3.5 & 3.7 & 3.8 & 4.2 & 4.5 & 4.2 & 3.6 & 3.4 & 3.5 & 4.0 & 3.9 \\
\hline & \multicolumn{12}{|c|}{ Fall season } \\
\hline Mean $(\mathrm{m} / \mathrm{s})$ & 7.4 & 6.9 & 6.8 & 7.0 & 7.0 & 8.1 & 8.8 & 8.4 & 8.3 & 7.8 & 7.4 & 7.5 \\
\hline Standard Deviation $(\mathrm{m} / \mathrm{s})$ & 3.7 & 3.5 & 3.6 & 3.7 & 3.8 & 4.2 & 4.4 & 3.9 & 3.6 & 4.0 & 4.0 & 3.5 \\
\hline
\end{tabular}

\subsection{Relation of power production and the microscale-spectral gap region}

In this section, we study the effect of wind speed mean time on the wind resource assessment at La Ventosa region. We assess, for the whole year, the influence of using different wind speed mean times in the wind resource assessment. This is obtained from the power spectrum analysis in Figure 7. the vertical red lines are the propose mean times: 1, 5, 10, 60, and 360 minutes, which captures the spectral gap and microscale regions. These mean times are used to calculate the wind power production (equation 2) and capacity factor (equation 3). 
Table 3 shows the capacity factor and the power production of the Vestas 90 wind turbine (Figure 10). An important assumption is that the mean wind speed is normal to the rotor wind turbine. The variation between wind speed mean time for the capacity factor, and wind turbine power production is not significant. This could be since the amplitude of the turbulent kinetic energy in the microscale region of the spectrum does not have a significant difference compared to the region of minimum energy, obtaining wind speed mean time values with a minimum dispersion.

Considering the power produced using 10 min wind speed mean time data as a reference value, the percentage error, $\frac{V_{\text {actual }}-V_{\text {reference }}}{V_{\text {reference }}} \times 100 \%$, has a maximum difference for the 1 minute mean time data of $-1.4 \%$. The negative sign in the difference column means an underestimation of the power production against the 10-min mean time. Thus, to perform a wind resource assessment using a 10-min or an hourly wind speed mean time has a good agreement and mean times must be chosen at least between the spectral gap and microscale region.

In terms of determining the annual energy production or capacity factor of a wind turbine, there is no a marked difference using a time series of 6 hours, 1 hour, or 1 minute. The latter is a consequence of a result that we

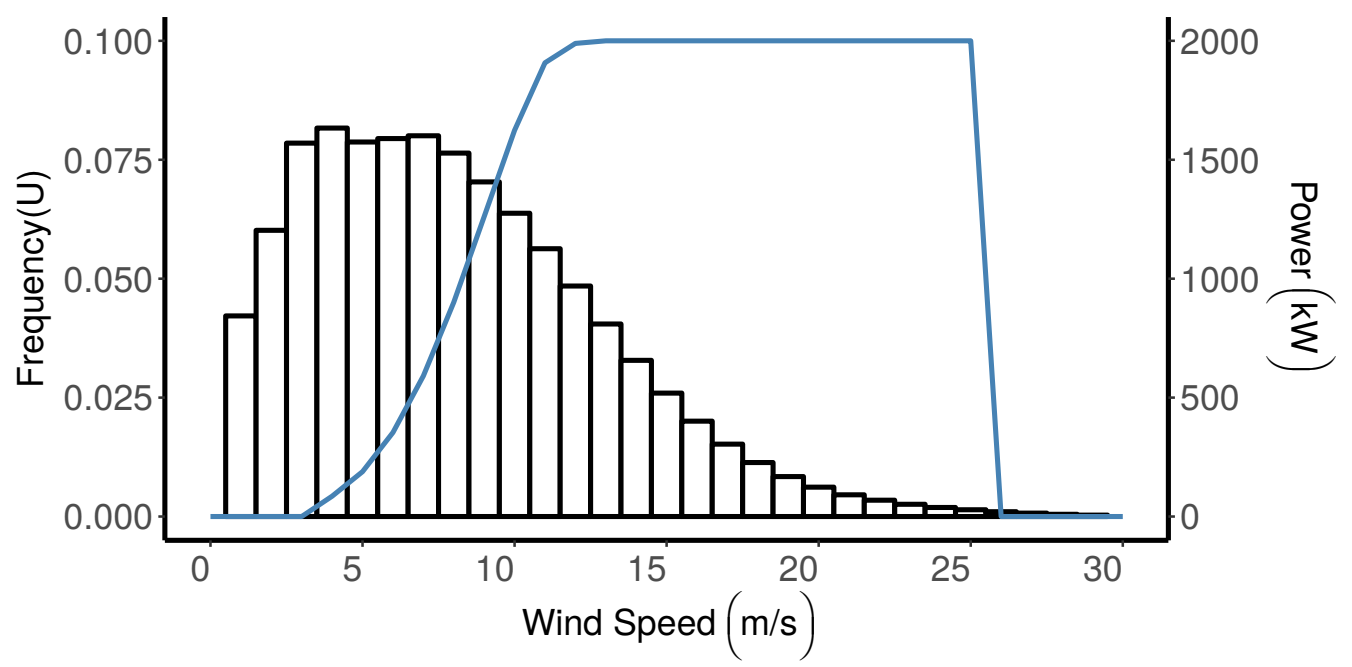

Figure 10: Power curve of the vestas90 and wind speed distribution for the period from August of 2017 to July of 2018. Nominal power of $2000 \mathrm{~kW}$, diameter of 90 meters, 3 blades and pitch power control. 
Table 3: Effect of the mean time on the capacity factor and power production of a wind turbine.

\begin{tabular}{cccc}
\hline Mean time & Capacity Factor (\%) & Power (kW) & Difference (\%) \\
\hline 1 minute & 48.6 & 972.4 & -1.4 \\
5 minutes & 49.2 & 983.4 & -0.2 \\
10 minutes & 49.3 & 985.5 & - \\
1 hour & 49.4 & 988.5 & 0.2 \\
6 hours & 49.5 & 989.9 & 0.4 \\
\hline
\end{tabular}

found in a previous section where the annual power spectrum does not have a significant amplitude difference in the spectral gap and the microscale region.

Now, the next step is to analyze whether the previous results might be just valid for the unique case of the annual power spectrum form found. We use the result shown in Figure 8, four power spectra clustered by season, to estimate the capacity factor for the same mean times. Each seasonal power spectrum shows a different behavior against the annual power spectrum, and we analyze, each of them, its influence in the wind resource assessment.

Table 4 shows the difference of the capacity factor using 10-minute wind speed average data as a reference value against 1, 5, 10, 60, and $360 \mathrm{~min}$ utes wind speed average. Here the sign is used to determine if whether it is a sub-estimation or overestimation. We found the maximum difference in Winter $(-1.69 \%)$, and spring $(-1.31 \%)$, and the lowest difference in spring $(-0.008 \%)$ and summer $(-0.13 \%)$. We can conclude that, at least for wind resource assessment, there is no a marked difference using a time series of 6 hours, 1 hour, or 1 minute.

Table 4: Seasonal difference of capacity factor of a wind turbine.

\begin{tabular}{ccccc}
\hline Mean time & $\begin{array}{c}\text { Winter } \\
\text { D i f f e r e n c e }(\%)\end{array}$ \\
\hline 1 minute & -1.69 & -1.28 & -1.14 & -0.79 \\
5 minutes & -0.28 & -0.24 & -0.13 & -0.10 \\
10 minutes & - & - & - & - \\
1 hour & 0.64 & 0.21 & -0.23 & 0.008 \\
6 hours & 1.44 & 0.67 & -0.26 & -1.31 \\
\hline
\end{tabular}

In the next section, we are going to explore the level of correlation of 
the measured data with the results of the numerical meteorological models. These models are a promising alternative to the complicated and expensive experimental wind measurement campaigns and to the long time needed to obtain a significant data set for analysis.

\subsection{A comparison of WRF model and data reanalysis against observations}

In this section, we performed a numerical simulation using the WRF model centered in La Ventosa, Oaxaca, as described in Section 2.2. The 415 output of this simulation was then used to generate a wind speed time series corresponding to the observation period (August 2017-July 2018). We also used the previously computed time series derived from the reanalyses MERRA-2 and ERA5.

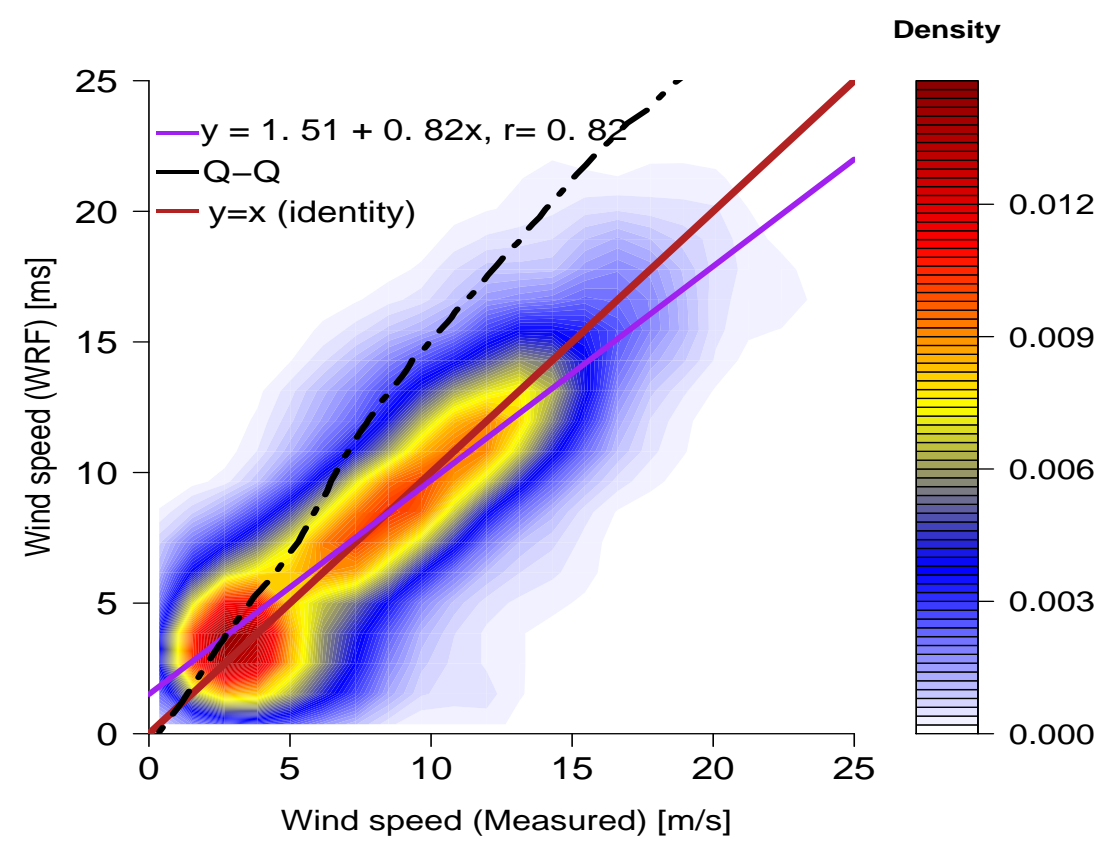

Figure 11: Comparison between measured data and WRF model. The linear equation for bias (purple straight line) correction has a correlation coefficient $r$ of 0.82 , which can be considered as a good approximation. The color mapping corresponds to the probabilistic density of the wind speed which shows an uni-modal behavior. It is also presented the identity line (dark-red line).

Figure 11 shows the linear adjustment lines and the linear equations for bias (purple straight line) correction with a correlation coefficient of $r=0.82$. 


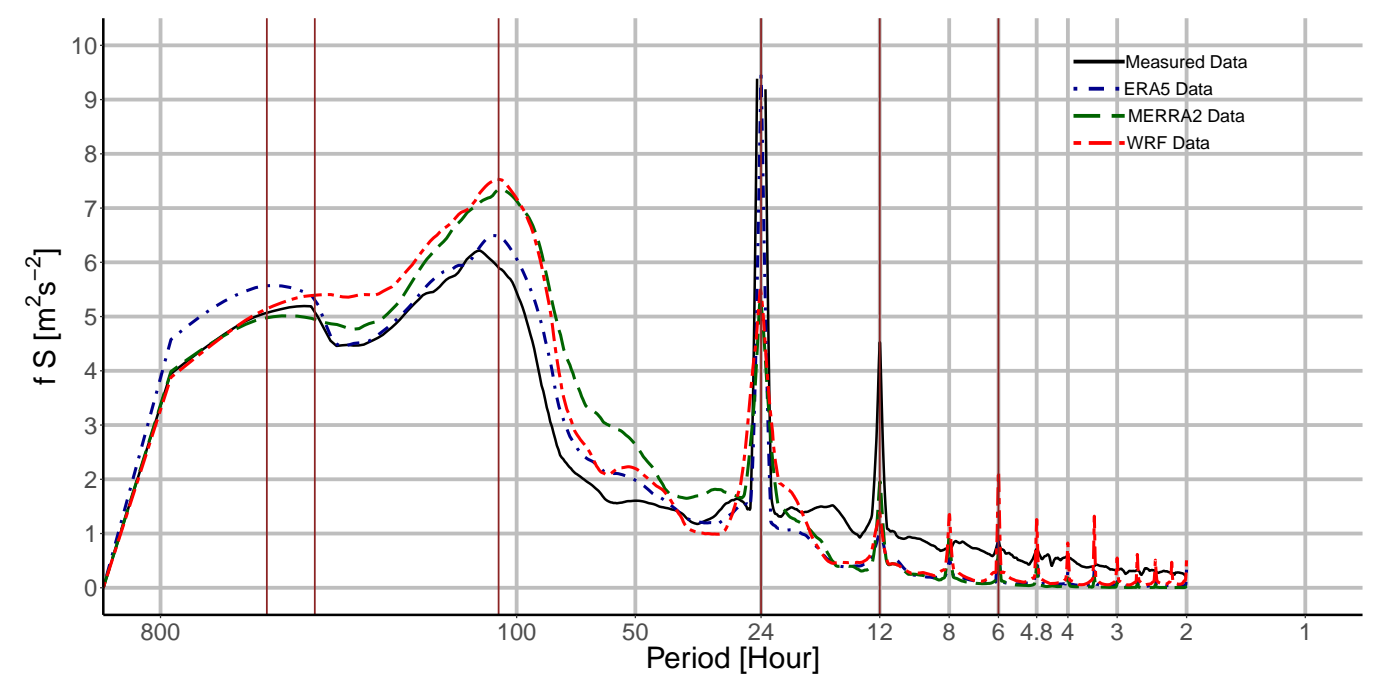

Figure 12: Comparison of the Power spectrum of the horizontal wind speed at La Ventosa, Oaxaca, Mexico between the 40 meters anemometer measured data set and ERA5, MERRA-2 and WRF data from August of 2017 to July of 2018. The microscale region and energy gap are clearly defined, as well as the diurnal effects at 12 hours and the peak corresponding to synoptic scale at 5.2 days and a peak at 16.7 and 27 days

The color mapping corresponds to the probabilistic density of the wind speed which shows an bi-modal behavior. The figure also shows the difference in quantiles-quantiles (Q-Q) of the measured data and the WRF model output. This Q-Q difference is higher than the MERRA-2 and ERA5 models (figure 5), which means a overstimation of the wind speed by the WRF model. All three models, figures 5 and 11, have correlation coefficient up to 0.75 , but the WRF correlation coefficient is higher than the other two models. The probability density of wind speed of MERRA-2 and ERA5 are similar between each other than WRF model. As the wind speed increases the Q-Q difference also increases, which can be interpreted as an overestimation of the wind speed.

Now, we determine the power spectrum of the bias-corrected models and compare at the 1 hour time resolution with the measured data. Figure 12 shows the power spectrum of the global models and measured data set. There is a peak at 27 days for the measured data, which the ERA 5 and WRF models also reproduce. The MERRA-2 model reproduced it at 16.7 days. It is easy to identify the synoptic peak at 5.2 days and the peaks at 24 and 12 hours. However, towards shorter periods, in the models appears a peak at 8 hours 
and several others. These peaks, at first, have similar amplitude and then

Table 5: Comparison between experimental data and models' results for the capacity factor with bias correction $\left(C F_{b c}\right)$ of a wind turbine.

\begin{tabular}{ccc}
\hline Data source & $\left(C F_{b c}\right)(\%)$ & Diff $_{C F_{b c}}(\%)$ \\
\hline Experimental data & 49.6 & - \\
WRF & 49.5 & 0.20 \\
ERA5 & 49.5 & 0.20 \\
MERRA-2 & 49.5 & 0.20 \\
\hline
\end{tabular}




\section{Conclusion}

In the present contribution, we implemented a power spectrum analysis for the region of La Ventosa using high-frequency measurements. From power spectrum results, we found a minimum variance region named spectral gap region in the wind power spectrum, which turns to be not so different in amplitude to the microscale region. We estimated the impact of the spectral gap and microscale regions on the wind resource assessment using 1, 510 , 60 , and 360 minutes mean-times, taking as a reference value the 10-minute mean-time. We found a maximum difference of $1.4 \%$ within 1 -minute against 10-minute. One of the main results is that, within 6-hour and 1-minute (spectral gap-microscale region), the power estimation differences results are not so great.

For each seasonal power spectrum analysis, we found a constant spectral gap region, center at 0.5 with an amplitude between 0.2 to $0.4 \mathrm{~m}^{2} \mathrm{~s}^{-2}$. The amplitude of the power spectrum varies through the season and reaching a maximum in winter. We conducted a power estimation using this seasonal power spectrum results to analyze whether the previous results might be just valid for the unique case of the annual power spectrum form found. We found that there is no difference using 6 hour or 1 minute mean times, and found similar results for each seasonal spectra against annual results.

We implemented WRF model simulations, along with two reanalyses: MERRA-2 and ERA5. As a first step, We determined the power spectrum of the numerical models, reproducing the synoptic peak, and the diurnal peaks at 24 and 12 hours. However, we found that the reanalysis and WRF model spectra, for periods shorter than around 1-day, started to deviate from that for measurements.

To determine the viability of using meteorological data, we calculated the capacity factor and the energy produced by a wind turbine using a manufacturer power curve. The maximum difference calculated against the measured data was $0.20 \%$ after implemented a bias correction. WRF and ERA5 model reports a lower difference capacity factor compared to the measured data. These might be due to the higher grid resolution dimensions. Thus, for our geographic region, the WRF model and reanalysis data can reproduce wind power production. 


\section{Acknowledgements}

The contributions by C.A. Lopez-Villalobos and O. Rodriguez-Hernandez were supported by project 272063, "Strengthening of the field of Wind Energy in the Doctoral Program in Engineering Field of Knowledge in Energy based in the Institute of Renewable Energies of the National Autonomous University of Mexico"; call, Institutional Strengthening for Energy Sustainability; and fund, CONACYT-SENER-Sustentabilidad Energética for supporting the development of this research work. O. Martínez-Alvarado's contribution was supported by a Newton Fund Institutional Links grant, ID 432335407, funded by the UK Department of Business, Energy and Industrial Strategy and delivered by the British Council, and by the UK National Centre for Atmospheric Science through the Atmospheric hazard in developing Countries: Risk assessment and Early Warning (ACREW) project. The authors thank Guillermo Hernández Cruz for both technical support and valuable recommendations, and Diego Canul for his valuable technical support with ERA5 and MERRA-2.

\section{References}

[1] D. Gielen, R. Gorini, N. Wagner, R. Leme, L. Gutierrez, G. Prakash, Global energy transformation: A roadmap to 2050, International Renewable Energy Agency, Abu Dhabi (2018) 76.

[2] G. W. E. C. GWEC, Global wind report: Annual market update 2019, URL https://gwec.net/global-wind-report-2019/.[Accessed May 17, 2020] (2019).

[3] E. Cadenas, W. Rivera, Wind speed forecasting in the south coast of oaxaca, mexico, Renewable energy 32 (12) (2007) 2116-2128. doi:https: //doi.org/10.1016/j.renene.2006.10.005.

[4] O. Jaramillo, M. Borja, Wind speed analysis in la ventosa, mexico: a bimodal probability distribution case, Renewable Energy 29 (10) (2004) 1613-1630. doi:https://doi.org/10.1016/j.renene.2004.02.001.

[5] C. Lopez-Villalobos, O. Rodriguez-Hernandez, R. Campos-Amezcua, G. Hernandez-Cruz, O. Jaramillo, J. Mendoza, Wind turbulence intensity at la ventosa, mexico: A comparative study with the iec61400 stan- 

en11113007.

[6] IEC61400-1, Wind turbines part 1: Design requirements, International Electrotechnical Commission, Geneva, Switzerland, 3rd Edition (2005).

[7] IEC61400-2, Wind turbines-Part 2. Small wind turbines, International Electrotechnical Commission, Geneva, Switzerland, 2nd Edition (2013).

[8] O. Rodriguez-Hernandez, J. Del Río, O. Jaramillo, The importance of mean time in power resource assessment for small wind turbine applications, Energy for Sustainable Development 30 (2016) 32-38. doi:https://doi.org/10.1016/j.esd.2015.10.008.

[9] A. B. Tabrizi, J. Whale, T. Lyons, T. Urmee, Rooftop wind monitoring campaigns for small wind turbine applications: Effect of sampling rate and averaging period, Renewable Energy 77 (2015) 320-330. doi:https://doi.org/10.1016/j.renene.2014.12.037.

[10] V. der Hoven Isaac, Power spectrum of horizontal wind speed in the frequency range from 0.0007 to 900 cycles per hour, Journal of me-

a teorology 14 (2) (1957) 160-164. doi:https://doi.org/10.1175/ 1520-0469(1957)014<0160: PSOHWS>2.0.CO;2.

[11] W. T. Chapman, Y. T. Sloan, The paths of hurricanes connie and diane, Mon. Wea. Rev 83 (1955) 171-180.

[12] H. Griffith, H. Panofsky, I. Van der Hoven, Power-spectrum analysis over large ranges of frequency, Journal of Meteorology 13 (3) (1956) 279-282. doi:https://doi.org/10.1175/1520-0469(1956) 013<0279:PSAOLR>2.0.CO;2.

[13] A. Panofsky Hans, A. McCormick Robert, Properties of spectra of atmospheric turbulence at 100 metres, Quarterly Journal of the Royal Meteorological Society 80 (346) (1954) 546-564. doi:https://doi.org/ $10.1002 / q j .49708034604$.

[14] H. Panofsky, I. Van der Hoven, Spectra and cross-spectra of velocity components in the mesometeorological range, Quarterly Journal of the

Royal Meteorological Society 81 (350) (1955) 603-606. doi:https:// doi.org/10.1002/qj.49708135010. 
[15] D. Lee, R. Baldick, Future wind power scenario synthesis through power spectral density analysis, IEEE Transactions on Smart Grid 5 (1) (2014) 490-500. doi:https://doi.org/10.1109/TSG.2013.2280650.

[16] E. Kaya, B. Barutcu, Ş. S. MENTEŞ, A method based on the van der hoven spectrum for performance evaluation in prediction of wind speed, Turkish Journal of Earth Sciences 22 (4) (2013) 681-689. doi:https: //doi.org/10.3906/yer-1207-1.

[17] C. L. Vincent, P. Pinson, G. Giebela, Wind fluctuations over the north sea, International Journal of Climatology 31 (11) (2011) 1584-1595. doi:https://doi.org/10.1002/joc.2175.

[18] S. Al-Yahyai, Y. Charabi, A. Gastli, Review of the use of numerical weather prediction (nwp) models for wind energy assessment, Renewable and Sustainable Energy Reviews 14 (9) (2010) 3192-3198. doi:https: //doi.org/10.1016/j.rser.2010.07.001.

[19] R. Chang, R. Zhu, M. Badger, C. Hasager, X. Xing, Y. Jiang, Offshore wind resources assessment from multiple satellite data and wrf modeling over south china sea, Remote Sensing 7 (1) (2015) 467-487. doi:https: //doi.org/10.3390/rs70100467.

[20] D. Carvalho, A. Rocha, M. Gómez-Gesteira, C. S. Santos, Wrf wind simulation and wind energy production estimates forced by different reanalyses: Comparison with observed data for portugal, Applied Energy 117 (2014) 116-126. doi:https://doi.org/10.1016/j.apenergy.2013. 12.001 .

[21] A. Simmons, Era-interim: New ecmwf reanalysis products from 1989 onwards, ECMWF Newsletter 110 (2006) 25-36. URL https://ci.nii.ac.jp/naid/10029113061/en/

590 [22] M. Rienecker Michele, J. Suarez Max, R. Gelaro, R. Todling, J. Bacmeister, E. Liu, G. Bosilovich Michael, D. Schubert Siegfried, L. Takacs, G.-K. Kim, Merra: Nasa's modern-era retrospective analysis for research and applications, Journal of climate 24 (14) (2011) 3624-3648. doi:https://doi.org/10.1175/JCLI-D-11-00015.1. 
[26] M. J. Brennan, H. D. Cobb III, R. D. Knabb, Observations of gulf of tehuantepec gap wind events from quikscat: An updated event climatol-

[23] M. Kanamitsu, W. Ebisuzaki, J. Woollen, S.-K. Yang, J. Hnilo, M. Fiorino, G. Potter, Ncep-doe amip-ii reanalysis (r-2), Bulletin of the American Meteorological Society 83 (11) (2002) 1631-1644. doi:https: //doi.org/10.1175/BAMS-83-11-1631.

[24] Copernicus Climate Change Service (C3S), ERA5: Fifth generation of ECMWF atmospheric reanalyses of the global climate. Copernicus Climate Change Service Climate Data Store (CDS), (accessed January 2020) (2017).

URL https://cds.climate.copernicus.eu/cdsapp\#!/home

[25] X. Hong, M. Peng, S. Wang, Q. Wang, Simulating and understanding the gap outflow and oceanic response over the gulf of tehuantepec during gotex, Dynamics of Atmospheres and Oceans 82 (2018) 1-19. doi: https://doi.org/10.1016/j.dynatmoce.2018.01.003. ogy and operational model evaluation, Weather and forecasting 25 (2) (2010) 646-658. doi:https://doi.org/10.1175/2009WAF2222324.1.

[27] R. Gelaro, W. McCarty, J. Suárez Max, R. Todling, A. Molod, L. Takacs, A. Randles Cynthia, A. Darmenov, G. Bosilovich Michael, R. Reichle, et al., The modern-era retrospective analysis for research and applications, version 2 (merra-2), Journal of Climate 30 (14) (2017) 5419-5454. doi:https://doi.org/10.1175/JCLI-D-16-0758.1.

[28] N. C. for Environmental Prediction/National Weather Service/NOAA/US Department of Commerce, Ncep fnl operational model global tropospheric analyses, continuing from july 1999, Research Data Archive at the National Center for Atmospheric Research, Computational and Information Systems Laboratory (2000). doi:https://doi.org/10.5065/D6M043C6.

[29] T. Lafon, S. Dadson, G. Buys, C. Prudhomme, Bias correction of daily precipitation simulated by a regional climate model: a comparison of methods, International Journal of Climatology 33 (6) (2013) 1367-1381. doi:https://doi.org/10.1002/joc.3518. 
[30] D. J. Thomson, Spectrum estimation and harmonic analysis, Proceedings of the IEEE 70 (9) (1982) 1055-1096. doi:https://doi.org/10. 1109/PROC.1982.12433.

[31] J. Thomson David, Nonstationary fluctuations in stationary time-series, in: Advanced Signal Processing Algorithms, Architectures, and Implementations IV, Vol. 2027, International Society for Optics and Photonics, 1993, pp. 236-244. doi:https://doi.org/10.1117/12.160438.

[32] M. Kay Steven, L. Marple Stanley, Spectrum analysis - a modern perspective, Proceedings of the IEEE 69 (11) (1981) 1380-1419. doi: https://doi.org/10.1109/PROC.1981.12184.

[33] P. Bronez Thomas, On the performance advantage of multitaper spectral analysis, IEEE Transactions on Signal Processing 40 (12) (1992) 29412946. doi:https://doi.org/10.1109/78.175738.

[34] A. J. Barbour, R. L. Parker, psd: Adaptive, sine multitaper power spectral density estimation for r, Computers \& Geosciences 63 (2014) 1-8. doi:https://doi.org/10.1016/j.cageo.2013.09.015.

[35] I. Papadakis, A. Lawrence, Improved methods for power spectrum modelling of red noise, Monthly Notices of the Royal Astronomical Society 261 (3) (1993) 612-624. doi:https://doi.org/10.1093/mnras/261. 3.612 .

[36] J. F. Manwell, J. G. McGowan, A. L. Rogers, Wind energy explained: theory, design and application, John Wiley \& Sons, 2010.

[37] M. Sathyajith, G. S. Philip, Advances in wind energy conversion technology, Springer Science \& Business Media, 2011.

[38] A. H. Oort, A. Taylor, On the kinetic energy spectrum near the ground, Monthly Weather Review 97 (9) (1969) 623-636.

[39] L. Telesca, M. Lovallo, M. Kanevski, Power spectrum and multifractal detrended fluctuation analysis of high-frequency wind measurements in 655 mountainous regions, Applied energy 162 (2016) 1052-1061. doi : https: //doi.org/10.1016/j . apenergy.2015.10.187. 
[40] E. D. Eggleston, Wind speed power spectrum analysis for bushland, texas 24 (1) (12 1996). doi:10.1260/0309524001495404.

[41] M. E. Soberanis, W. Mérida, Regarding the influence of the van der hoven spectrum on wind energy applications in the meteorological mesoscale and microscale, Renewable Energy 81 (2015) 286-292. doi:https://doi.org/10.1016/j.renene.2015.03.048.

[42] A.-S. Smedman-Högström, U. Högström, Spectral gap in surfacelayer measurements, Journal of the Atmospheric sciences 32 (2) (1975) 340-350. doi:https://doi.org/10.1175/1520-0469(1975) $032<0340$ : SGISLM $>2.0$. CO 2 .

[43] O. Magaña Víctor, L. Vázquez Jorge, L. Pérez José, J. B. Pérez, Impact of el niño on precipitation in mexico, Geofísica internacional 42 (3) (2003) 313-330.

[44] R. Romero-Centeno, J. Zavala-Hidalgo, A. Gallegos, J. J. O'Brien, Isthmus of Tehuantepec Wind Climatology and ENSO Signal, Journal of Climate 16 (15) (2003) 2628-2639. doi:https://doi.org/10.1175/ 1520-0442(2003)016<2628: IOTWCA>2.0.CO;2.

[45] A. Prósper Miguel, I. Sosa Tinoco, C. Otero-Casal, G. Miguez-Macho, Downslope windstorms in the isthmus of tehuantepec during tehuantepecer events: a numerical study with wrf high-resolution simula-

1 tions, Earth System Dynamics 10 (3) (2019) 485-499. doi:https: //doi.org/10.5194/esd-10-485-2019.

[46] J. Olauson, Era5: The new champion of wind power modelling?, Re680 newable energy 126 (2018) 322-331. doi:https://doi.org/10.1016/ j.renene.2018.03.056.

[47] W. C. Skamarock, Evaluating mesoscale nwp models using kinetic energy spectra, Monthly weather review 132 (12) (2004) 3019-3032. doi:https://doi.org/10.1175/MWR2830.1.

[48] J. Olauson, H. Bergström, M. Bergkvist, Restoring the missing highfrequency fluctuations in a wind power model based on reanalysis data, Renewable energy 96 (2016) 784-791. doi:https://doi.org/10.1016/ j.renene.2016.05.008. 